I have been surprised at the common ground between management development and psychiatry: transactional analysis, gestalt, listening skills, positive belief cycles. Although my knowledge of this common ground is sketchy, my postgraduate psychiatric training has already re-kindled management skills that six years of medical school and house jobs conspired to obliterate. In addition, much of the course material is directly applicable to my clinical work.

I am not concerned about what is 'required of me' as a manager but rather what I require of my organisation. I also realise that I have had a range of effective management skills for years, without being aware of them, and that I can continue to develop them in the light of future needs. All of my colleagues in training have extensive management ability, but rarely acknowledge this fact themselves. Management training can help us to improve existing talents, and it is up to us to critically appraise, and choose, the courses which suit our needs.

The General Infirmary

DAvid Yeomans

Leeds LSI 3EX

\section{Management training}

DeAr SirS

Dr Jadresic's paper on management training (Psychiatric Bulletin, February 1992, 16, 86-87) serves as an important reminder of controversy surrounding management training for clinicians. Griffiths management reform is not just about a few doctors becoming general managers, but about all doctors becoming managerially accountable for the quality of their service and the resources they commit (Waters, 1985). The trend towards cost-efficiency and competition within internal markets further strengthens the case for the acquisition of effective management skills. The CTC working party report on management training (1990) provides a review of available alternatives and makes recommendations useful for those contemplating management training. Any trainee embarking on management training should consider very carefully the alternatives, assess their needs and determine their own aims and objectives. It is often necessary to choose and/or tailor an individual training package.

Even those "with a prioritised and single interest in clinical practice and research" need to realise that the acquisition of management skills is an on-going experience which starts early in one's career, and may usefully be supplemented by attending selected courses.

O. JUNAID

Queen's Medical Centre

Nottingham NG7 2UH

\section{References}

The CTC Working Party Report on Management Training (1990). Psychiatric Bulletin, 14, 373-378.

WATERS, H. (1985) Management training for clinicians. British Medical Journal, 291, 1294-1295.

\section{DeAr Sirs}

I was interested to read Dr Jadresic's article entitled 'Management Training - what do we need?' (Psychiatric Bulletin, February 1992, 16, 86-87) where it was suggested that doctors might learn more about management by following a manager around for the day than on a formal course. I would support this suggestion for registrars/senior registrars, after spending a day "attached" to our Unit General Manager. It involved numerous meetings with many health professionals (clinicians and management) between $8.30 \mathrm{a} . \mathrm{m}$. and 7.30 p.m. I came to understand much more about management issues, Trust funds and the skills involved in chairing meetings etc.

I also made my contribution, giving unsolicited advice on the dangers of excessive caffeine intake and hypoglycaemia. We didn't stop for lunch.

St Edward's Hospital, Cheddleton

G. M. KEARNEY

(Keele Registrar Rotational Training Scheme)

\section{Patient involvement in their psychiatric care}

Dear Sirs

In response to the concerns I raised in the wake of the MIND People First survey, Drs Phaterpekar and Abbott (Psychiatric Bulletin, February 1992, 16, 112-113) suggest that I "should be reassured that considerable advances have been made with regard to patient involvement in their psychiatric care". May I make the following points?

(a) Local monitoring of satisfaction with services by those delivering care is confounded by the issue of power. A positive response bias is likely when people in hospital are asked their views by those who control their therapeutic fate and, in the case of formally detained patients, their liberty. Our survey was a research exercise, as we were independent of service delivery and this could explain why our data offer much less comfort to clinicians about the quality of in-patient services, as assessed by users. If psychiatrists are really concerned with service quality I hope that they give due attention to this in the research funding bodies they control. For instance, in the list of priorities set by the MRC committee looking at research into "schizophrenia" in 1988, service evaluation to patients (not by them) came a lame 8 out of 10 targets. Traditional 